\title{
EFFECT OF DIFFERENT LAYUP SEQUENCES ON VIBRATION RESPONSE OF KENAF CORE REINFORCED COMPOSITE FOAM
}

\author{
M.Y. YUHAZRI ${ }^{1}$,M.H. AMIRHAFIZAN ${ }^{2}$,N.H. SULAIMAN ${ }^{3}$, L.S. FOON ${ }^{4}$ \\ ${ }^{1,4}$ Faculty of Mechanical and Manufacturing Engineering Technology, \\ ${ }^{2}$ Faculty of Manufacturing Engineering, Universititeknikal Malaysia Melaka, Hang Tuah Jaya, 76100 Durian
} Tunggal, Melaka, Malaysia.

${ }^{3}$ Department of Mechanical Engineering, Politeknikmerlimau, KB.1031, Pejabatposmerlimau, 773000 Merlimau Melaka, Malaysia.

\begin{abstract}
Recently, the use of natural resources tends to replace the use of synthetic resources in the composite field. The natural resource has comparable mechanical properties compared to the synthetic resource. An experimental investigation was conducted to investigate the effect of different layup sequences of different mesh sizes of kenaf core $(\mathrm{KC})$ reinforced composite foam. Composite foam was manufactured using a simple process of mixing and cold pressing to ensure the equivalent thickness of the composite foam formed. A total of 27 layup sequences with two types of resin used were soft epoxy (SE) and polyurethane (PU). $3.0 \mathrm{~mm}, 20$ mesh and 30 mesh of KC size were used and the motor vibration test was used to evaluate the performance of the composite foam. Based on the results, it was found that most of the specimens of reinforced PU composites had better vibration energy absorption properties compared to the specimens of reinforced SE composites. The BAC layup sequence reinforced PU composite shows good agreement in vibration energy absorption properties, which improved $64.78 \%$ compared to pure PU foam. It was also found that the $3.0 \mathrm{~mm}$ mesh size of the KC used showed better performance in the absorption of vibration energy.

KEYWORDS: KC, Mesh Size, Polyurethane, Soft Epoxy, Composite
\end{abstract}

Received: Jun 08, 2020; Accepted: Jun 28, 2020; Published: Sep 16, 2020; Paper Id.: IJMPERDJUN20201278

\section{INTRODUCTION}

In recent years, there has been an increasing interest in the use of natural fibre as reinforcement in the field of composite materials. Natural fibres can be categorized into three types according to their origin, i.e. animal fibre, plant fibre and mineral fibre [1]. There is a large volume of published studies describing the use of natural fibres in a variety of ways. According to the review presented by Pickering et al. [2], natural fibre composites have been used in many areas such as the aircraft and automotive industries, toys, funerals, marine railings, electronic equipment and sports equipment.Rohit and Dixit[3] also stated that natural fibre was also used in windows, furniture, automotive panels and gardening products due to its light weight, low price and low maintenance requirements.

In addition, there are abundant natural fibres that can be obtained from plants such as kenaf, sisal, cotton, hardwood, etc. However, the focus of this study will be on the kenaf plant. The Kenaf plant comes from the Hibiscus Cannabinus family [4]. In addition, kenaf is also a potential crop to replace tobacco in Malaysia due to the tropical climate in Malaysia that was suitable for kenaf cultivation, as indicated in the comprehensive review of Journey of Kenaf in Malaysia by Basri et al. [5]. Tezara et al. [6] have stated that the containment of cellulose and 
hemicellulose in the kenaf plant will influence the mechanical properties of the material when it is reinforced in the composite material.Kenaf plants have an enormous potential to be used in engineering applications [7]. Akil et al. [8] mentioned that $\mathrm{KC}$ can be used as summer forage, animal bedding, and potting medium. In addition, Saad and Kamal [9] have stated that $\mathrm{KC}$ can also be used for the production of composite insulation, medium density particle boards, fire retardant particle boards, polymer composites, thermoacoustic applications and sound barrier due to its light and porosity properties. Porosity is very important as it determines the ability of the composite material to absorb energy as it refers to the amount of cell form in a material that can help to absorb energy. Radzi et al. [10] also proposed that the mesh core size used as a filler would influence the interfacial bonding of the composites due to the contact of its surface area with the matrix.

In addition, Arenas and Crocker[11] argued that porous material may be used to reduce noise and vibration produced by machinery, vibration isolation, barriers, sound absorbing materials, machine enclosures or cabin enclosures. They also stated that the porous characteristics of the materials have a high value of the sound absorption coefficient. This finding was consistent with the findings of past studies by Dhanapal and Kannan[12], which indicated that the most effective shock absorption materials are in footwear, polyurethane foam and elastomer. The proposed concentration of polyol and dissociate will influence foam density and cushioning, the more closed macro cellular structure will be achieved and the higher cushioning capacity will result.Berardi and Iannace [13] indicated that the material must have a high porosity as a characteristic for absorbing sound. They also describe that the closed pores in the material allow only minimal sound absorbency, while the open pores, which have a continuous channel to the surface of the material, have higher sound absorbency.

Moreover, Ashan et al. [14] studies on the preparation and characterization of natural fiber-filled asphalt based damping material. The sample was tested under a temperature range of $-100^{\circ} \mathrm{C}$ to $50^{\circ} \mathrm{C}$ and a constant frequency of $1 \mathrm{~Hz}$. They found that asphalt composite with 10 wt. \% of kenaf fibre as reinforcement has the highest damping capability. The damping capability of the composite indicates the amount of damping peak amplitude that can be reduced. The higher the reduction of the damping peak amplitude, the more energy was dissipated during the damping mechanism.Shan et al. [15] used PU polymer composite reinforced coir fibres and recycled tires to enhance the damping and vibrational characteristics of the seat foam. They found that after the fillers were added, more vibration was dissipated by the foam composites developed. Composite foam was also found to provide better vibration damping at resonance compared to conventional seat cushions used in the Proton car.To the best knowledge of the author, many interesting results have been reported on the potential of natural plants in the use of vibration. However, most studies in open literature did not simultaneously examine the effect of different layup sequences of different mesh sizes of KC reinforced PU and SE composites. This was the motivation behind the current study.

\section{MATERIALS AND METHODOLOGY}

$\mathrm{KC}$ as a reinforcement was the raw materials used in this study. Three (3) KC types of $3.0 \mathrm{~mm}, 20$ mesh and 40 mesh, as illustrated in Figure 1. LembagaKenaf\&Tembakau Negara, Malaysia (LKTN) supplied the KC. The KC prices for $3.0 \mathrm{~mm}$, 20 mesh and 40 mesh respectively were MYR850, MYR900 and MYR1100 per ton. The PU and SE have meanwhile been used as a matrix. Table 1 and Table 2 showed the properties of PU and SE. Ultimate Panel (M) Sdn. Bhd. provided the PU used in this research. The prices for PU and SE were MYR15.00 and MYR90.00 respectively per kilogram. The different mesh sizes of the $\mathrm{KC}$ used were dried in the oven at $115^{\circ} \mathrm{C}$ for 6 hours before the manufacturing process. This process is 
intended to remove the humidity content of the $\mathrm{KC}$. The bonding between the $\mathrm{KC}$ and the matrix was also improved by this process.In addition, for all kinds of PU or SE reinforced composites the thickness of each composite sample was set to $10.00 \mathrm{~mm}$. The composite reinforced PU and SE layup sequences were 27 types with different types of $\mathrm{KC}$ sizes as shown in Table 3. The example of layup sequences of different KC sizes is shown in Figure 2.

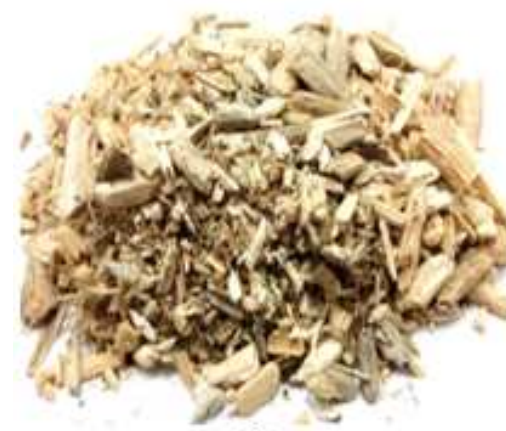

(a)

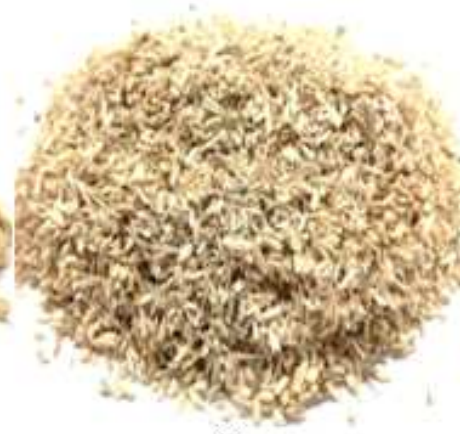

(b)

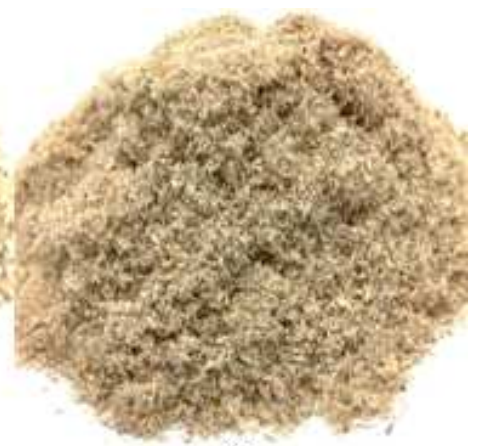

(c)

Figure 1: KC Mesh Sizes (A) 3.0 Mm; (B) 20 Mesh; (C) 40 Mesh

Table 2: Properties of SE

\begin{tabular}{|l|l|l|}
\hline & \multicolumn{1}{|c|}{ Resin } & \multicolumn{1}{c|}{ Hardener } \\
\hline Appearance & Clear liquid & Clear liquid \\
\hline Viscosity (CPS) & $3,000-4,000 \mathrm{cps}$ & $180-220 \mathrm{cps}$ \\
\hline Mixing ratio & $3: 1$ & $3: 1$ \\
\hline Pot life $\left(25{ }^{\circ} \mathrm{C}\right)$ & 30 minutes & 30 minutes \\
\hline \multirow{2}{*}{ Curing condition } & $\begin{array}{l}12 \text { hours with } 25^{\circ} \mathrm{C} \\
\text { Heating }: 1 \text { hour } 15 \text { minutes with } 60^{\circ} \mathrm{C}\end{array}$ \\
\hline Shelf life & 6 months \\
\hline Flash point & More than $300^{\circ} \mathrm{C}$ & More than $150^{\circ} \mathrm{C}$ \\
\hline
\end{tabular}

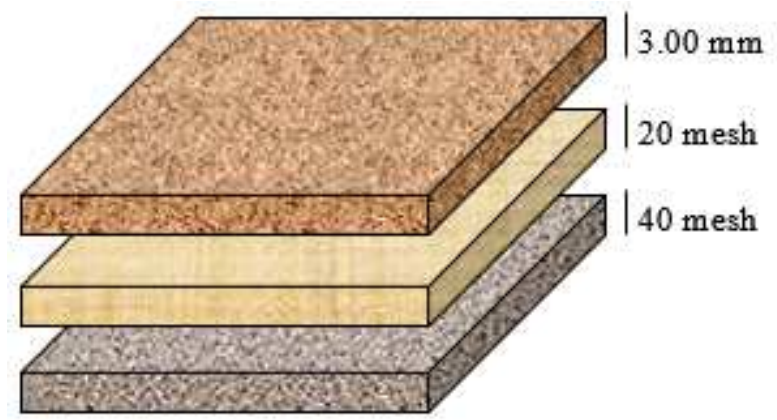

Figure 2: Example of Layup Sequences of Different Sizes of the KC

In addition, the engine vibration test was used to evaluate the energy absorption of KC composite foam. Samples were cut into $160 \mathrm{x}$ into $120 \mathrm{x} 10 \mathrm{~mm}$ depending on the engine base size. The frequency of vibration of the engine was set to $100 \mathrm{kHz}$. The accelerometer was then placed on top of the engine. When the engine is on, the accelerometer starts detecting the vibration of the motor and all the results obtained have been graphically represented. 
Table 3: Layup

Sequences of Different

Sizes of the KC

\begin{tabular}{|c|c|c|}
\hline AAA & BAA & CAA \\
\hline AAB & BAB & CAB \\
\hline AAC & BAC & CAC \\
\hline ABA & BBA & CBA \\
\hline ABB & BBB & CBB \\
\hline ABC & BBC & CBC \\
\hline ACA & BCA & CCA \\
\hline ACB & BCB & CCB \\
\hline ACC & BCC & CCC \\
\hline
\end{tabular}

Note: $A$ is $3.00 \mathrm{~mm}$; $B$ is 20

mesh; $C$ is 40 mesh

\section{RESULT AND DISCUSSIONS}

\section{Vibration Performance of KC Reinforced PU}

From the data in Figure 3, the BAC layup sequence specimen had the lowest mean amplitude value of 0.230, which was $64.78 \%$ lower than that of pure PU foam. The mean amplitude of the AAC layup sequence was 0.257 , the second highest, followed by an ACA layup sequence specimen with 0.267 . The mean amplitude value decreased by $60.64 \%$ and $59.11 \%$ compared to pure PU foam. In addition, the specimen with the ABB and AAB layup sequences had the same average amplitude value, which was 0.283 , which also decreased $56.66 \%$ compared to pure PU foam. However, the BCB layup sequence shows the highest mean amplitude value of 0.970 , which was $32.68 \%$ higher than pure PU foam. There were 0.733 and 0.650 of the mean amplitude values represented by the ACB and ABA layup sequence specimens. It represents $12.25 \%$ higher and $0.46 \%$ lower than the average amplitude of pure PU foam.

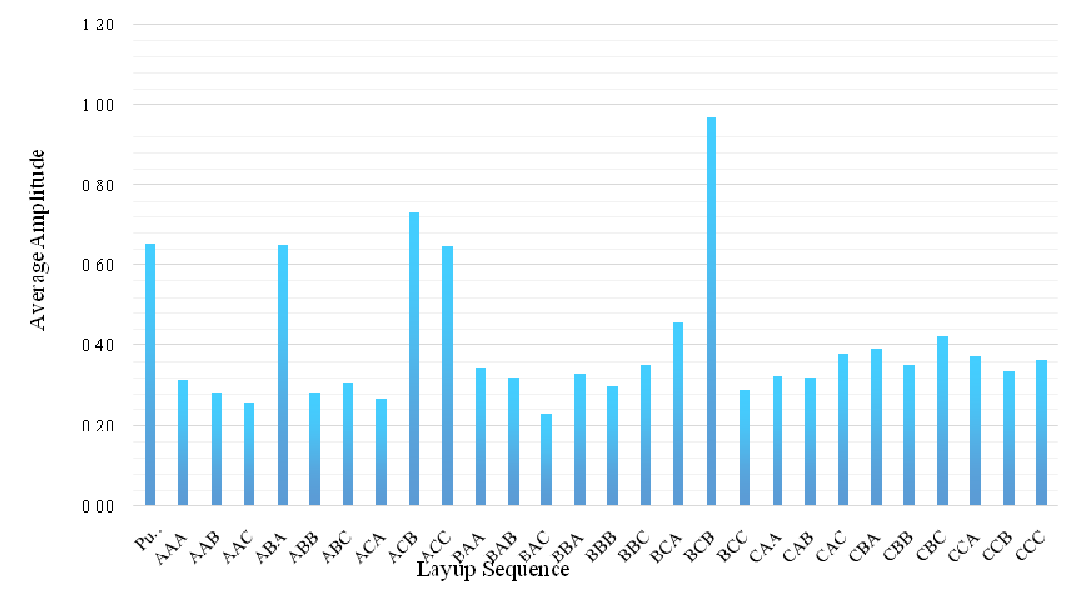

Figure 3: The Average Amplitude of Pure PU and 27 Layup Sequence of KC Reinforced PU.

From the result obtained, the mean amplitude value of specimens with a double layer of $3.0 \mathrm{~mm} \mathrm{KC}$ mesh reinforced PU was shown to be lower in their layup sequence. However, most of the sequencing specimens that used a double layer of 20 mesh sizes of KC reinforced PU have a higher average amplitude value. The lower mean amplitude value obtained by PU reinforced $3.0 \mathrm{~mm}$ mesh size $\mathrm{KC}$ was due to its content of more open pores due to the quantity of $\mathrm{KC}$ per $\mathrm{cm}^{3}$ for the larger mesh size KC less than the smaller mesh size $\mathrm{KC}$. In addition, the larger mesh size of the $\mathrm{KC}$ cannot mix well with the PU and cause the PU reinforced with the $3.0 \mathrm{~mm}$ mesh size of the KC formed by a higher number 
of open pores compared to the 40 mesh size of the KC reinforced PU which is smaller enough to mix with the PU. The increase in the amount or size of the natural filler content used in PU composite foam causes a decrease in the average cell size of PU foam and leads to an increase in cell distribution in addition to the formation of more closed pores in PU composite foam [16-17].

\section{Vibration Performance of KC Reinforced SE}

Figure 4 shows that the result obtained from the CBA layup sequence specimen had the lowest mean amplitude value of 0.25 , which was $61.54 \%$ lower than the pure SE specimen. The mean amplitude for the BCC specimen was 0.28 , which was the second lowest, followed by the BCB layup sequence specimen with 0.29 . The mean amplitude value of the pure SE specimen was $56.92 \%$ and $55.38 \%$ lower. In addition, the sample layup sequence BBB and BBC has a mean amplitude value of 0.36 and 0.37 . The difference in the mean amplitude value of these layup sequences to the pure SE specimen showed $44.62 \%$ and $43.08 \%$ declination. However, the CCA layup sequence was the highest in average amplitude between the different layup sequences, which was 4.43 . It was $581.54 \%$ higher than the pure SE specimen. The mean amplitude value of the specimen with the layup sequence CCC and BCA was 4.00 and 3.87. Compared to pure SE specimens, $515.38 \%$ and $495.38 \%$ have increased by an average amplitude value. For the CAC and CBB layup sequences, there was a total increase of $464.62 \%$ and $458.62 \%$ in the mean amplitude relative to the pure SE specimen. The mean amplitude value obtained by both of these layup sequences through the engine vibration test was 3.67 and 3.63 , respectively.

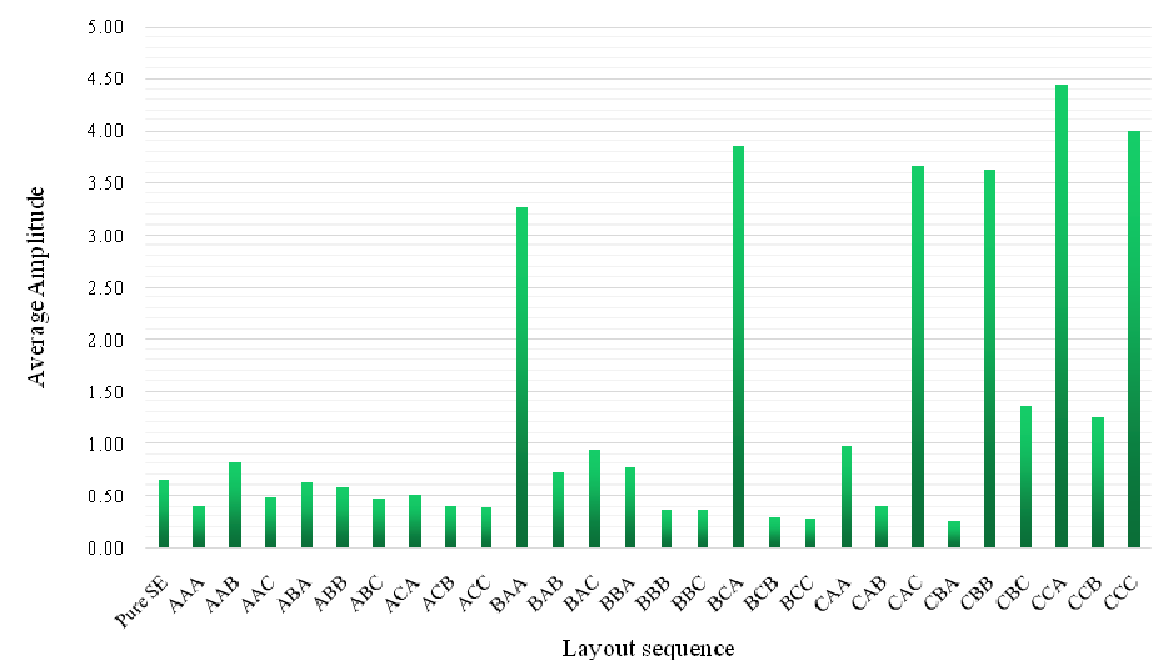

Figure 4: The Average Amplitude of Pure SE and 27 Layup Sequence of KC Reinforced In SE.

In addition, from the five lowest and five highest average amplitude values obtained between the different layup sequences, the layup sequence specimen having 20 mesh sizes as the top layer has a lower average amplitude value. The reason for these layup sequence specimens has a lower mean amplitude value was because the KC size used to reinforce the $\mathrm{SE}$ was medium in size. The medium size $\mathrm{KC}$ was of an average size which could form more micro void when reinforced in SE compared to $3.0 \mathrm{~mm}$ and 40 mesh sizes of $\mathrm{KC}$ which were too large and too small to form enough micro void within the SE composite structure. This theory was supported by Hanan et al. [18] who argued that the uneven distribution of fibre caused the resin to consist of higher amounts of micro void and air bubbles. As a result, it can be shown that the layup sequence specimen with 20 mesh size $\mathrm{KC}$ as the top layer has better vibration absorption as the 
average amplitude value of these specimens was lower than the other layup sequences. Moreover, the bonding structure of $\mathrm{KC}$ reinforced SE does not have a foamy texture and therefore only a minimum amount of micro void and air bubbles can be found. As a result, the SE specimens with 20 mesh $\mathrm{KC}$ as reinforcement on the top layer for the layup sequence were most effective for the energy dissipated during the engine vibration test.

\section{Vibration Performance of KC Reinforced PU and SE}

Figure 5 shows a comparison of the mean amplitude values of $\mathrm{KC}$ reinforced $\mathrm{PU}$ and SE composites. All specimens with $\mathrm{KC}$ reinforced PU had a lower mean amplitude value through the engine vibration test compared to the KC reinforced SE composite. The lower mean amplitude value for the specimens indicated that the lower vibration was detected during the engine vibration test. Therefore, from Figure 5, KC reinforced PU has better absorption of vibration energy compared to KC reinforced SE composite. The reason for this is the different bonding structure of the PU and SE. In the case of reinforced SE composite specimens, the crosslink density contained in the specimens was higher due to the higher number of epoxy groups present. The epoxy material has a high cross-linking density due to the bulk of the epoxy groups. Thus, epoxy has better mechanical properties [19], but the crosslink present in KC reinforced SE does not have a foamy structure that contains closed pores. As a result, the overall KC reinforced PU specimen showed a lower mean amplitude value, which meant better vibration energy absorption properties compared to the KC reinforced SE specimen.

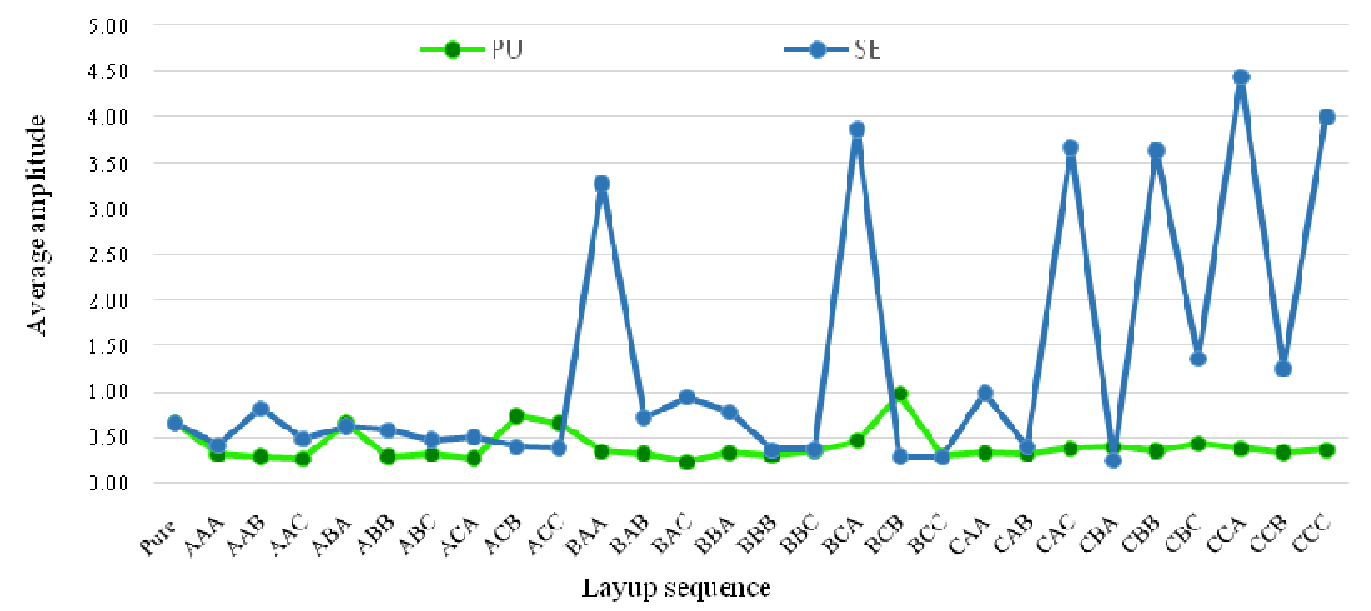

Figure 5: Comparison of Average Amplitude for KC Reinforce PU and KC Reinforced SE.

\section{Microstructure of Specimen Reinforced PU and SE Composites}

Figure 6 shows the microstructure of all KC reinforced PU and SE composites. The microstructure of the pure PU specimen is shown in Figure 6(a). It has been shown that the pure PU specimen is made up of multiple pores linked together. Pores that are contained in PU foam can help in the transfer of energy when the energy is applied to it. The pure SE microstructure can be found in Figure 6 (b). The pure SE specimen has a flat surface and does not contain pore on the specimen. This is because the bonding structure present in SE is a cross-linked structure. The molecules in SE were packed tightly together. As a result, the pure SE specimen has lower vibration energy absorption under the engine vibration test. Figure 6(c) shows the $3.0 \mathrm{~mm} \mathrm{KC}$ reinforced PU microstructure. Most PU reinforced $3.0 \mathrm{~mm}$ mesh size KC specimens at the top have higher vibration energy absorption because the larger size of the $\mathrm{KC}$ is too large and cannot be distributed evenly when the PU is reinforced and the larger size of the $\mathrm{KC}$ also causes the quantity of $\mathrm{KC}$ per $\mathrm{cm}^{3}$ to be lower than the smaller KC. As a result, a higher number of open pores were formed in the specimen. 

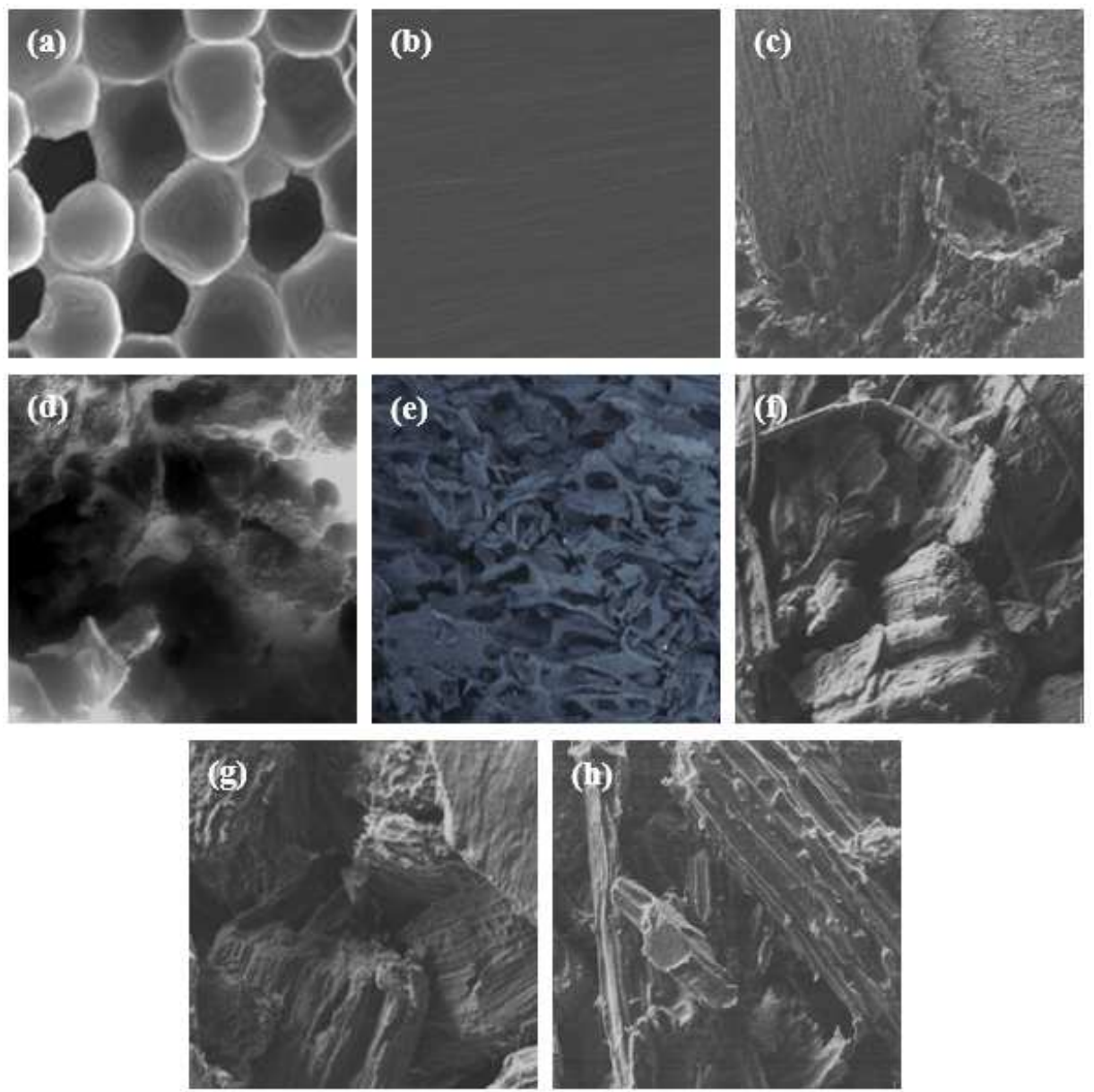

Figure 6.SEM Image Of (A) Pure PU; (B) Pure SE; (C) 3.0 Mm Size Of KC Reinforced PU; (D) 20 Mesh Size Of KC Reinforced PU; (E) 40 Mesh Size Of KC Reinforced PU; (F) 3.0 Mm Size Of KC Reinforced SE; (G) 20 Mesh Size Of KC Reinforced SE; (H) 40 Mesh Size Of KC Reinforced SE.

In addition, the lower amount of open pore was found in the 20 mesh size $\mathrm{KC}$ reinforced PU microstructure as shown in Figure 6 (d). This is because the smaller size of the $\mathrm{KC}$ was used as a reinforcement and most of the pores formed in the PU were enclosed by the KC. The vibration energy absorption properties of this specimen were therefore improved. Figure 6 (e) showed that all pores formed in PU were filled with KC and almost all of the pore structure was closed, which was less efficient in the absorption of vibration energy. Figure 6 (f) declared the structure of the specimen under the SEM observation, and the large void formed between the KC can be seen. However, due to the large size of the $\mathrm{KC}$ used and the stronger bonding structure formed between the $\mathrm{KC}$ and SE resin, this composite specimen could not absorb much vibration energy. Numerous smaller voids have been observed between the bonding of the KC structure as shown in Figure $6(\mathrm{~g})$. Without the foaming structure, the impact energy can only be absorbed and reduced during the energy transformation within the void area created between the $\mathrm{KC}$ bonding structures. Due to the smaller mesh size of the $\mathrm{KC}$ used as reinforcement, more micro void can be formed and contributes to the enhancement of vibration energy absorption properties. In addition, a sample of 40 mesh sizes of $\mathrm{KC}$ was shown in Figure 6 (h). When undergoing SEM observation, the SE specimen with 40 mesh size $\mathrm{KC}$ as reinforcement shows the least amount of void between the $\mathrm{KC}$ bonding structure. The underlying cause was the small size of the KC used as a SE reinforcement. As the KC size was small, it can therefore blend well with SE to form a compact and stronger bonding structure. This caused the vibration energy absorption properties of this specimen to be weakest compared to the two other specimens that reinforced the $3 \mathrm{~mm}$ 
and 20 mesh sizes of $\mathrm{KC}$.

\section{CONCLUSIONS}

The present study was designed to determine the effect of different layup sequences of different mesh sizes of KC reinforced composite foam. These studies have shown that the specimens that make up the PU have better vibration-energy absorption properties compared to the specimen made of KC reinforced SE composites. This was due to the more open pore content in the PU foam that makes the energy spread to the pore. $235.71 \%$ of the vibration energy absorption capacity was increased when compared to the average vibration energy absorption of specimens made up of PU resin and SE resin. It was also shown that the best vibration absorbent composite foam was the BAC layup sequence specimen. This was because it can absorb the most amount of vibration energy compared to other sequencing specimens, even with different resins used. As a result, the BAC layup sequence specimen has an enormous potential to replace the current market motorcycle seat cushion due to its higher vibration energy absorption properties. In addition, enhanced KC in PU also bring environmental benefits such as reducing the amount of PU used in production, reducing the weight of the cushion and biodegradable reinforced $\mathrm{KC}$.

\section{ACKNOWLEDGEMENT}

Authors would like to thank Skim ZamalahUTeM for financial support and and Ministry of Energy, Science, Technology, Environment and Climate Change by providing Grant PRGS/2/2019/TK03/UTEM/02/2.

\section{REFERENCES}

1. Peças, P., Carvalho, H., Salman, H., \&Leite, M. (2018). Natural fibre composites and their applications: a review. Journal of Composites Science, 2(4), 66-86

2. Pickering, K. L., Efendy, M. A., \& Le, T. M. (2016). A review of recent developments in natural fibre composites and their mechanical performance.Composites Part A: Applied Science and Manufacturing, 83, 98-112.

3. Rohit, K., \& Dixit, S. (2016). A review-future aspect of natural fiber reinforced composite. Polymers from Renewable Resources, 7(2), 43-59.

4. VENKATEGOWDA, T., and MANJUNATHA LH. "FREE VIBRATION CHARACTERISTICS OF ALKALI TREATED UNIDIRECTIONAL LONG KENAF FIBER REINFORCED EPOXY COMPOSITES AT VARIOUS END CONDITIONS. "International Journal of Mechanical and Production Engineering Research and Development (IJMPERD) 9. 4, Aug 2019, 1245-1254

5. Ramesh, M. (2016). Kenaf (Hibiscus cannabinus L.) fibre based bio-materials: A review on processing and properties. Progress in Materials Science, 78, 1-92.

6. Basri, M. H. A., Abdu, A., Junejo, N., Hamid, H. A., \& Ahmed, K. (2014). Journey of kenaf in Malaysia: A Review. Scientific Research and Essays, 9(11), 458-470.

7. Tezara, C., Siregar, J. P., Lim, H. Y., Fauzi, F. A., Yazdi, M. H., Moey, L. K., \& Lim, J. W. (2016). Factors that affect the mechanical properties of kenaf fiber reinforced polymer: A review. Journal of Mechanical Engineering and Sciences, 10(2), $2159-2175$.

8. Prasad, P. Rajendra, J. N. Prakash, and L. H. Manjunath."MECHANICAL CHARACTERIZATION OF EPOXY/POLYETHYLENE FIBERREINFORCED COMPOSITES." International Journal of Mechanical and Production Engineering Research and Development (IJMPERD) 8.8 (2018): 271-276.

9. Yuhazri, M. Y., Amirhafizan, M. H., Abdullah, A., Yahaya, S. H., Lau, S. T. W., \&Kamarul, A. M. (2018). Kenaf fibre composites as promising green-composites for automotive car door map pocket application. International Journal of Mechanical and Mechatronics Engineering, 18(2), $15-21$.

10. Akil, H., Omar, M. F., Mazuki, A. A. M., Safiee, S. Z. A. M., Ishak, Z. M., \& Bakar, A. A. (2011). Kenaf fiber reinforced composites: A review. 
Materials \& Design, 32(8-9), 4107-4121.

11. Saad, M. J., \& Kamal, I. (2012). Mechanical and physical properties of low density kenaf core particleboards bonded with different resins. Journal of Science and Technology, 4(1), 17-32.

12. Golshahr, Alireza, et al. "Multiwall carbon nanotube reinforced silicone for aerospace applications." Int. J. Mech. Prod. Eng. Res. Dev 8.4 (2018): 743-752.

13. Radzi, M. K. F. M., Muhamad, N., Akhtar, M. N., Razak, Z., \& MOHD, F. (2018). The effect of kenaf filler reinforcement on the mechanical and physical properties of injection moulded polypropylene composites. SainsMalaysiana, 47(2), 367-376.

14. Arenas, J. P., \& Crocker, M. J. (2010). Recent trends in porous sound-absorbing materials. Sound \& vibration, 44(7), 12-18.

15. Dhanapal, D., \& Raja, K. (2016). PU memory foam for application as insole in therapeutic footwear for patients with diabetes.International Journal of Engineering Science, 6(6), 7784-7785.

16. Berardi, U., \&Iannace, G. (2015). Acoustic characterization of natural fibers for sound absorption applications.Building and Environment, 94, 840-852.

17. Natrayan, L., Maharshi Singh, and M. Senthil Kumar. "An experimental investigation on mechanical behaviour of SiCp reinforced Al 6061 MMC using squeeze casting process." Inter J Mech Prod Engi Res Develop 7.6 (2017): 663-668.

18. Ahsan, Q., Hui, W.T., Othman, I.S., Jun, L.P. \& Putra, A. (2018). Preparation and Characterization of Natural Fiber Filled Asphalt Based Damping Material. Journal of Advanced Research in Fluid Mechanics and Thermal Sciences, 47(1), 8-15.

19. Shan, C. W., Ghazali, M. I., \& Idris, M. I. (2013). Improved vibration characteristics of flexible polyurethane foam via composite formation. International Journal of Automotive and Mechanical Engineering, 7, 1031-1042.

20. Choe, H., Sung, G., \& Kim, J. H. (2018). Chemical treatment of wood fibers to enhance the sound absorption coefficient of flexible polyurethane composite foams. Composites Science and Technology, 156, 19-27.

21. Zieleniewska, M., Leszczyński, M. K., Szczepkowski, L., Bryśkiewicz, A., Krzyżowska, M., Bień, K., \&Ryszkowska, J. (2016). Development and applicational evaluation of the rigid polyurethane foam composites with egg shell waste. Polymer Degradation and Stability, 132, 78-86.

22. Hanan, U.A., Hassan, S.A., Wahit, M.U., Rozali, A.R.M., Mohamad, H.K.B. \&Lazi, M.A.M. (2016). Mechanical properties of glass fiber waste/kenaf core reinforced unsaturated polyester eco-friendly composite. Journal of Built Environment, (1), 1-9.

23. Yamini, S., \& Young, R. J. (1980). The mechanical properties of epoxy resins.Journal of materials science, 15(7), 1823-1831. 

